\title{
Level-2 Milestone 2351: \\ Terascale Simulation Facility Upgrade
}

\section{Milestone report for NNSA HQ}

Prepared by Anna Maria Bailey

September 30, 2007 
This document was prepared as an account of work sponsored by an agency of the United States Government. Neither the United States Government nor the University of California nor any of their employees, makes any warranty, express or implied, or assumes any legal liability or responsibility for the accuracy, completeness, or usefulness of any information, apparatus, product, or process disclosed, or represents that its use would not infringe privately owned rights. Reference herein to any specific commercial product, process, or service by trade name, trademark, manufacturer, or otherwise, does not necessarily constitute or imply its endorsement, recommendation, or favoring by the United States Government or the University of California. The views and opinions of authors expressed herein do not necessarily state or reflect those of the United States Government or the University of California, and shall not be used for advertising or product endorsement purposes.

This work was performed under the auspices of the U.S. Department of Energy by University of California, Lawrence Livermore National Laboratory under Contract W-7405-Eng-48. 


\section{Table of Contents}

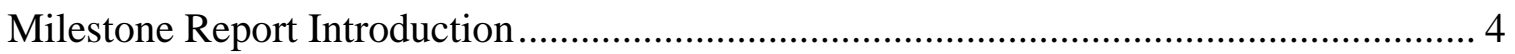

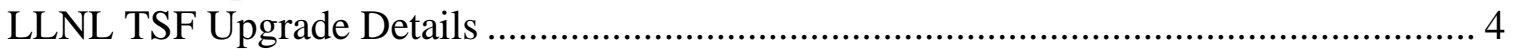

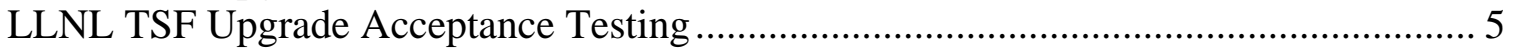

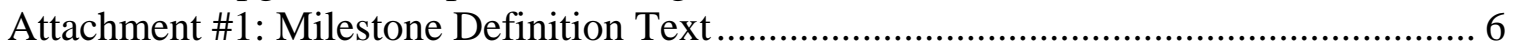

Attachment \#2: Project Quarterly Reports...................................................................... 7

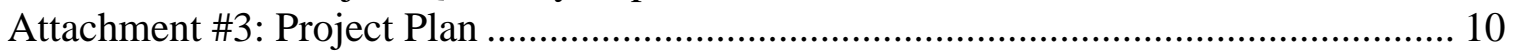




\section{Milestone Report Introduction}

This report documents the LLNL TSF upgrade ASC L2 milestone 2351: Terascale Simulation Facility upgrade, due Sept. 30, 2007. The full text of the milestone is included in Attachment 1. The stated goal of the milestone was:

Complete a 3-MW expansion of electrical power for computing systems in the east computer room of the Terascale Simulation Facility (TSF) and complete the final connection of all air handlers that were delivered as part of the TSF line item.

In this report we detail the upgrade and cover the results of the process to accept the system by testing, adjusting, balancing and finally start-up of the system in accordance with the detailed project commissioning plan to be developed by the system engineers during the design phase of the project.

The quarterly reports for the upgrade and the text of the project commissioning plan are included at the end of this document as Attachments 2 and 3.

\section{LLNL TSF Upgrade Details}

The 3MW expansion consisted of installing the final computational electrical capacity of the electrical distribution system in the east room to achieve an overall computational power level of 7.5MW. The scope of the project included commissioning two $13.8 \mathrm{kV}-$ 480/277V, 1500kVA medium voltage transformers, installing over 8 miles of secondary electrical cable from the electrical yard into the first level of the machine room for the low voltage distribution, six secondary 500kVA distribution transformers, six secondary low voltage switchboards, low voltage conduit/raceways, and 36 panelboards on the second level of the machine room. The project also included the final connection of (2) 80,000 CFM air handlers to be fully commissioned once the direct digital control system is upgraded in FY08. The air handlers are not needed to support the increase in electrical capacity, they will not come on line until FY08.

3MW of increased capacity will provide 26,280 MWh of energy annually for computational load. This available energy capability can provide enough energy to serve about 2400 average sized homes. The project was to increase the overall capability of the computational electrical capacity to TSF to site future platforms.

The secondary distribution is highly scalable and flexible and can be distributed at $480 \mathrm{~V}$ or $208 / 120 \mathrm{~V}$. This project installed $1.5 \mathrm{MW}$ at $480 \mathrm{~V}$ and $1.5 \mathrm{MW}$ at $208 / 120 \mathrm{~V}$. General Electric and Underwriter's Laboratory completed a certification of the 
switchboards and panelboards for multi-voltage ratings. The switchgear and panelboards are now dually rated for applications at $600 \mathrm{~V}$ and below. Both $480 \mathrm{~V}$ and $208 \mathrm{~V}$ electrical distribution is within the range of the multi-voltage rating application.

The 3MW expansion completed on 9/25/07 upon completion of the panelboard installation and associated inspections. The panelboards are fully energizable upon Program demand. The mechanical portion of the project (air handler hookup) was complete on 9/21/07 after final inspections. The air handler hookup is complete though not fully available until the direct digital control system is upgraded in FY08; the direct digital control system upgrade is outside the scope of this milestone.

\section{LLNL TSF Upgrade Acceptance Testing}

The inspection and acceptance testing of the electrical power distribution equipment is performed in accordance with NETA ATS - 2007, which is an acceptance testing specification published by InterNational Electrical Testing Association. The inspection and testing procedures clearly define the following:

Scope

Applicable References

Qualifications of Testing Organization and Personnel

Power System Studies

System Function Test

Thermo graphic Survey

Expected Test Results

Visual and mechanical inspection

Electrical tests

Test values

The visual and mechanical inspections are complete and are documented by the Subcontractor and verified by the Facility Management staff. The electrical tests and the compilation of the tests are in progress with an independent third party testing agency. 


\section{Attachment \#1: Milestone Definition Text}

Milestone (ID\#): Terascale Simulation Facility upgrades (\#2351)

Level: 2

Fiscal Year: FY07

DOE Area/Campaign: ASC

Completion Date: Sep-07

ASC nWBS Subprogram: Facility Operations and User Support

Participating Sites: LLNL

Description: Complete a 3-MW expansion of electrical power for computing systems in the east computer room of the Terascale Simulation Facility (TSF) and complete the final connection of all air handlers that were delivered as part of the TSF line item.

Completion Criteria: The completion criteria is to fully accept the system by testing, adjusting, balancing and starting-up the system in accordance with the detailed project commissioning plan to be developed by the system engineers during the project design phase.

Customer: ASC Program

Milestone Certification Method: Completion evidence will be documentation and Program hand-off.

\section{Supporting Resources: N/A}

Codes/Simulation Tools Employed: N/A

Contribution to the ASC Program: Enables the TSF to site next generation ASC capability and capacity systems.

\section{Contribution to Stockpile Stewardship:}

\begin{tabular}{|c|c|c|c|c|}
\hline \multirow{2}{*}{ No. } & \multirow{2}{*}{ Risk Description } & \multicolumn{3}{|c|}{ Risk Assessment (low, medium, high) } \\
\hline & & Consequence & Likelihood & Exposure \\
\hline 1 & $\begin{array}{l}\text { Operations of the east computer room } \\
\text { will be impacted during physical } \\
\text { construction. }\end{array}$ & Medium & High & \\
\hline 2 & $\begin{array}{l}\text { The direct digital control (DDC) system } \\
\text { commissioning of air handlers will } \\
\text { require significant contingency planning } \\
\text { to ensure existing operations are not } \\
\text { impacted. }\end{array}$ & Medium & High & \\
\hline
\end{tabular}




\section{Attachment \#2: Project Quarterly Reports}

The following entries were reported as quarterly reports in the ASC Site Work Plan for this project.

Due Date: FY07 Q4

Planned Milestone Budget: 22578.0

Q1

Status: Green

Progress Narrative: Q1 Achievements October - December - Successfully prioritized FY07 projects and received ranking from the Facility Governance Board (FGB) to proceed on various elements that make up the 3MW completion to the East Computer Room in B-453. - Design complete for the following 3MW projects: $0 \mathrm{~T}-1851$ and $\mathrm{T}-186013.8 \mathrm{kV}-480 / 277 \mathrm{~V}$ Medium Voltage Connections 0 $1851 \mathrm{~A}$ and 1860A Low Voltage Feeder Distribution o (2) 80,000 CFM Air Handler Connections \&\#8211; Electrical/Mechanical/Controls - Purchased (6) $500 \mathrm{kVA}$ secondary transformers for the $480 \mathrm{~V}$ distribution. Scheduled to arrive April 20, 2007.

Q2

Status: Green

Progress Narrative: Q2 Achievements January - March Design complete for the final 3MW element: 0 Computational Utilization Distribution and Panelboard Installation - Finalized Form $1 \mathrm{~s}$ and Job Orders for all of the 3MW project elements. Work scheduled with Labor Only and on track to complete in middle of Q4: O T-1851 and $\mathrm{T}-186013.8 \mathrm{kV}$ - 480/277V Medium Voltage Connections $\circ 1851 \mathrm{~A}$ and 1860A Low Voltage Feeder Distribution 0 (2) 80,000 CFM Air Handler Connections \&\#8211; Electrical/Mechanical/Controls o Computational Utilization Distribution and Panelboard Installation Specifications complete for the 36 panelboards for the East Room. Purchase Order in progress. - Purchase Order complete with General Electric to certify the switchboards for multi-voltage ratings. 
Q3:

Status: Green

Progress Narrative: Q3 Achievements April - June $\mathrm{T}-1851$ and $\mathrm{T}-186013.8 \mathrm{kV}$ - 480/277V Medium Voltage Connections have started and the project is about $25 \%$ complete.

1851A and 1860A Low Voltage Feeder Distribution is 75\% complete.

(6) 500kVA secondary transformers and associated switchgear for the secondary distribution is 95\% complete.

(36) panelboards for the East Room are being installed. Conduit from switchgear to panelboards is complete ready to accept conductor installation. Entire task is $45 \%$ complete.

General Electric is in process of certifying switchboards and panelboards for multi-voltage ratings in preparation of UL inspection visit.

(2) 80,000 CFM Air Handler Connections - Mechanical connections complete and electrical distribution to begin. Project is 50\% complete.

Q4:

Status: Blue

Progress Narrative: Q4 Achievements July - September $\mathrm{T}-1851$ and $\mathrm{T}-186013.8 \mathrm{kV}$ - 480/277V Medium Voltage Connections are 100\% complete. Certified and inspected by Computation Facility Management staff.

1851A and 1860A Low Voltage Feeder Distribution is 100\% complete. Certified and inspected by Computation Facility Management staff.

(6) 500kVA secondary transformers and associated switchgear for the secondary distribution is 100\% complete. Certified and inspected by Computation Facility Management staff.

(36) panelboards for the East Room are being installed. Conduit from switchgear to panelboards is complete ready to accept conductor installation. Entire task is 
$100 \%$ complete. Certified and inspected by Computation Facility Management staff.

General Electric and UL are complete in certifying switchboards and panelboards for multi-voltage ratings. Certified and inspected by Computation Facility Management staff.

(2) 80,000 CFM Air Handler Connections - Mechanical connections complete and electrical distribution in progress. Project is 90\% complete. Certified and inspected by Computation Facility Management staff. 


\section{Attachment \#3: Project Plan}

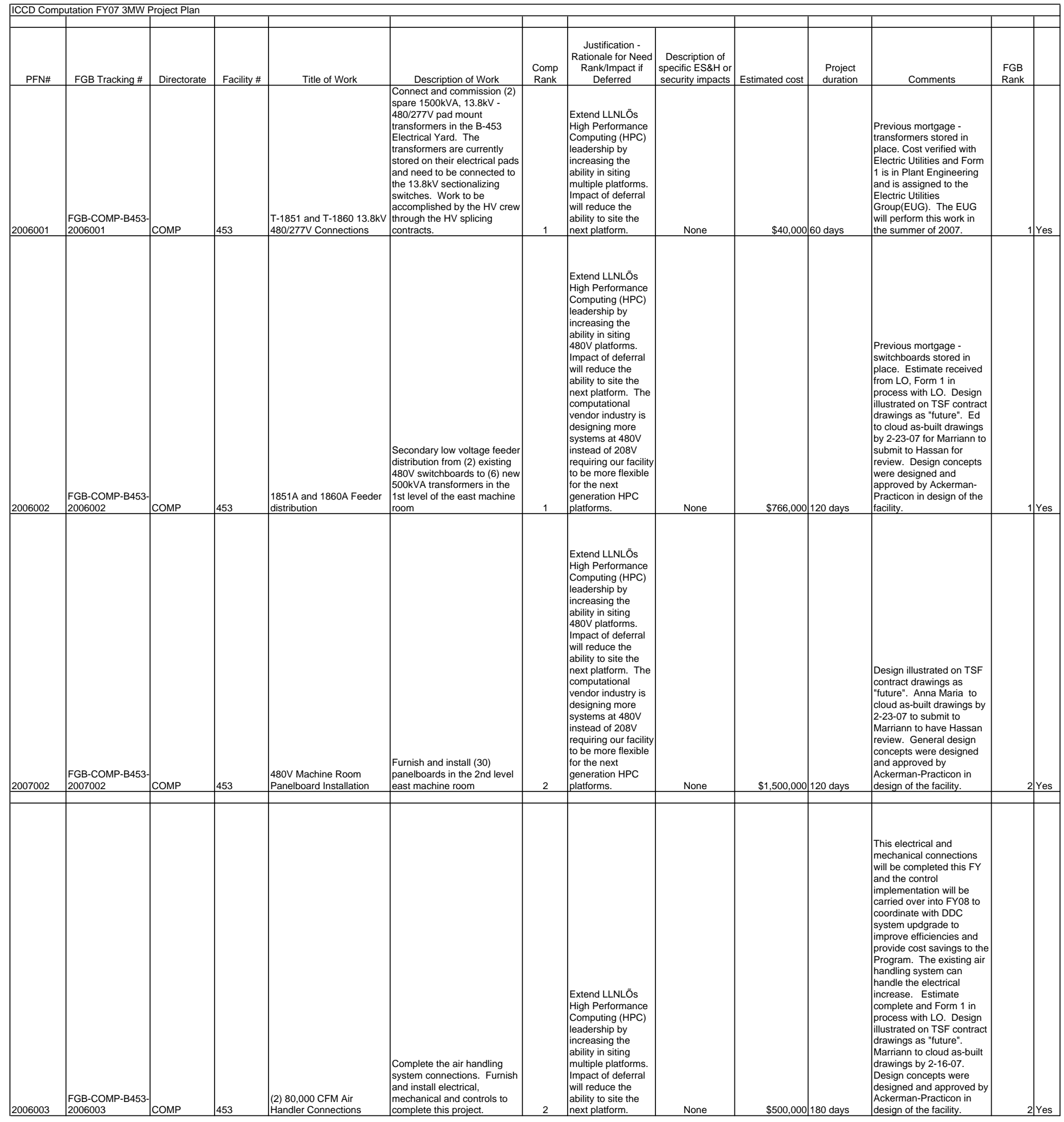

